Société d'histoire de la révolution de 1848 et des

révolutions du XIXe siècle

$43 \mid 2011$

L'ordre électoral : savoirs et pratiques

\title{
Casey HARISON, The Stonemasons of Creuse in Nineteenth-Century Paris, Newark, University of Delaware Press, 2008, 331 p. ISBN : 978-0-87413-020-1. 65 dollars.
}

Iorwerth Prothero

\section{(2) OpenEdition \\ Journals}

Édition électronique

URL : http://journals.openedition.org/rh19/4184

DOI : $10.4000 /$ rh 19.4184

ISSN : $1777-5329$

Éditeur

La Société de 1848

Édition imprimée

Date de publication : 13 novembre 2011

Pagination : 167-169

ISSN : 1265-1354

\section{Référence électronique}

Iorwerth Prothero, «Casey HARISON, The Stonemasons of Creuse in Nineteenth-Century Paris, Newark, University of Delaware Press, 2008, 331 p. ISBN : 978-0-87413-020-1. 65 dollars. », Revue d'histoire du XIXe siècle [En ligne], 43 | 2011, mis en ligne le 13 juillet 2012, consulté le 22 septembre 2020. URL : http://journals.openedition.org/rh19/4184; DOI : https://doi.org/10.4000/rh19.4184

Ce document a été généré automatiquement le 22 septembre 2020

Tous droits réservés 


\section{Casey HARISON, The Stonemasons of Creuse in Nineteenth-Century Paris, Newark, University of Delaware Press, 2008, 331 p. ISBN : 978-0-87413-020-1. 65 dollars.}

Iorwerth Prothero

Pendant plusieurs siècles, on le sait, la région de moyenne montagne enclavée et pauvre qui devint le département de la Creuse, envoya ses hommes chercher du travail ailleurs. Bien avant la Révolution, un courant de migration saisonnière s'était établi : du printemps à l'automne, les hommes partaient travailler, essentiellement comme maçons et surtout à Paris, et revenaient passer l'hiver chez eux. En 1830, ils furent ainsi 24000 Creusois à gagner la capitale, et leur nombre continua d'augmenter jusqu'à atteindre un maximum de 42000 en 1876. Année après année, de père en fils, ils venaient se loger dans les modestes garnis du centre-ville surpeuplé. De leur région d'origine, ils conservaient le parler, l'habit, le régime alimentaire, vivant de peu, à l'écart des autres ouvriers, épargnant l'essentiel de leurs salaires pour rembourser les emprunts et faire vivre leurs familles au village. Chaque jour, ceux qui cherchaient un emploi se rendaient sur la place de Grève pour s'offrir aux employeurs ou à leurs agents, sans garantie de trouver toujours à s'embaucher. L'âge venant, ils se retiraient dans leur village natal, pour vivre sur le lopin qu'ils avaient pu acquérir. La grande restructuration de Paris sous le Second Empire attira un nombre croissant de travailleurs du bâtiment, tout en modifiant la vie de ces immigrants, évincés du centreville, comme le marché de l'embauche quotidienne. À partir des années 1880, les familles de maçons commencèrent à suivre les hommes à Paris, où l'installation prit un tour définitif, entraînant l'intégration des Creusois dans la société urbaine. À la veille de la Grande Guerre, la migration saisonnière, les garnis et le marché de la Grève, 
étaient choses du passé ; les Creusois devenaient des Parisiens, laissant les gros travaux de construction à des immigrants plus récents.

2 Ce livre étudie en détail ce fascinant phénomène au cours d'un long XIX ${ }^{e}$ siècle, en se fondant sur une vaste bibliographie, et d'une manière globalement rigoureuse et claire, même si la relecture des épreuves laisse un peu à désirer. Toutefois, s'il s'agit d'une enquête en profondeur sur l'industrie du bâtiment à Paris, sur l'immigration, l'haussmannisation ou encore sur la protestation ouvrière, les aperçus généraux tendent à prendre le pas sur l'étude des Creusois eux-mêmes, et ceux-ci disparaissent même quasiment dans les chapitres concernant le marché de l'emploi (marchandage) ou les mouvements de 1848. L'auteur convient lui-même qu'il n'entre guère dans la vie concrète des maçons à Paris, conservant un point de vue essentiellement surplombant, du fait même des sources qu'il utilise : bulletins de police, enquêtes économiques, articles de journaux, et surtout les dossiers des maçons arrêtés pour agitation ou rébellion après les insurrections des années 1830, de 1848 et de 1871 .

Assez rapide sur les migrations elles-mêmes ou sur le versant rural de la vie des Creusois de Paris, le livre l'est aussi sur leur place précise dans les structures du travail parisien. D'où sans doute la traduction trompeuse de «maçon » par «stonemason». En Angleterre, le métier qu'on appelait masonry englobait les opérations de coupe, de taille et de sculptage de la pierre de construction, et les stonemasons maitrisaient à la fois cet art et l'érection des murs en pierre. Or en France, on distinguait les tailleurs de pierre que le livre ignore pratiquement - des maçons proprement dits, qui ne faisaient qu'assembler la pierre ou la brique, ouvriers peu qualifiés qu'en Angleterre on appelait wallers (et non masons). Le terme stonemason n'est donc pas approprié à un cadre français, pas plus qu'à un cadre irlandais d'ailleurs, où l'on distinguait également entre stonecutters, très qualifiés, et brick and stone setters, simples « maçons ».

L'un des points les plus intéressants que soulève le livre concerne la suspicion particulière dont les maçons venus de la campagne et entassés dans les vieux quartiers centraux, étaient l'objet. Dans le Paris du XIX ${ }^{\mathrm{e}}$ siècle, les travailleurs du bâtiment avaient bien une réputation de violence, et entraient pleinement dans la conception des "classes dangereuses». Chaque jour, on l'a dit, ils se rassemblaient nombreux devant l'Hôtel de Ville, sur cette place étroitement associée aux journées révolutionnaires, et par ailleurs théâtre des exécutions capitales jusqu'en 1832. Ainsi, bien que jugés plutôt dociles par les patrons et les autres ouvriers, la police et le public pouvaient considérer les Creusois comme des nomades potentiellement mécontents et menaçants, disponibles pour l'émeute. De fait, à partir de 1815, la place de Grève est attentivement surveillée et les maçons plus que tous autres, la police jaugeant à leur nombre et à leurs dispositions des risques d'agitation sociale ou politique. En réalité, les maçons n'étaient pas particulièrement turbulents, délinquants ni séditieux, même si l'attitude de la police pouvait conduire à des tensions, mais leur réputation les désignait plus que d'autres à la répression, notamment après les journées de juin 1848 et après la Commune. Comme le montre l'auteur, en effet, le nombre d'ouvriers rapidement relâchés souligne l'arbitraire des opérations de police et leur disproportion avec les faits poursuivis. À la fin du siècle, quand les Creusois cessèrent d'être Parisiens par intermittence, et la situation politique se stabilisant, l'image publique des maçons s'améliora. Cette question de la réputation et de la répression est à bien des égards le cœur de l'ouvrage, mais comme les maçons n'étaient pas réellement des acteurs majeurs des émeutes, on peut se demander s'il s'agissait vraiment d'un angle d'attaque 
adéquat; et l'argument selon lequel la méfiance de la police contribuait à pousser ces ouvriers vers le conflit et la rébellion, ne parait pas au total très étayé. Plus largement, l'approche de la propension particulière des Parisiens à la révolte, attribuée à l'imposition par l'État d'un marché libéral, parait trop rapide et imprécise. On peut donc reprocher au livre, outre un titre erroné, un traitement limité de son objet, plus attaché à la perception des maçons qu'aux maçons eux-mêmes, trop souvent perdus dans des développements d'ordre général.

traduit de l'anglais par Gilles Malandain 